\title{
МЕТОДИЧЕСКИЕ АСПЕКТЫ ПОСТРОЕНИЯ СИСТЕМЫ ВНУТРЕННЕГО КОНТРОЛЯ НА ОСНОВЕ ЗАКОНА SARBANES-OXLEY
}

\author{
(С) 2021 Сидорова М.И. \\ доктор экономических наук, доцент, заместитель декана по научной работе \\ Факультета международных экономических отношений, \\ руководитель научно-учебной лаборатории «ANAPLAN (Analitical Planning)» \\ Финансовый университет при Правительстве Российской Федерации, Россия, Москва \\ E-Mail: MISidorova@fa.ru \\ (C) 2021 Голубкина В.И. \\ студентка Факультета международных экономических отношений, \\ Научно-учебная лаборатория «ANAPLAN (Analitical Planning)» \\ Финансовый университет при Правительстве Российской Федерации, Россия, Москва \\ E-mail: sgolubkina@mail.ru
}

Закон Sarbanes-Oxley (SOX) был принят в США еще в 2002 году с целью защитить инвесторов от мошеннических действий со стороны руководства организаций в отношении составляемой последними финансовой отчетности. Главным требованием данного законодательного акта является построение и функционирование в экономических субъектах, ценные бумаги которых зарегистрированы Комиссией по ценным бумагам и биржам США (SEC), эффективной системы внутреннего контроля за формированием финансовой отчетности.

Ключевые слова: учет, анализ, аудит, автоматизация, моделирование, система внутреннего контроля, риск-ориентированный подход.

Закон Sarbanes-Oxley (SOX) был принят в США еще в 2002 году с целью защитить инвесторов от мошеннических действий со стороны руководства организаций в отношении составляемой последними финансовой отчетности. Главным требованием данного законодательного акта является построение и функционирование в экономических субъектах, ценные бумаги которых зарегистрированы Комиссией по ценным бумагам и биржам США (SEC), эффективной системы внутреннего контроля за формированием финансовой отчетности*.

Внутренний контроль за составлением финансовой отчетности (ВКФО) является одним из элементов более широкой общепринятой международной концепции внутреннего контроля, которая была разработана Комитетом спонсорских организаций Комиссии Тредуэя (COSO) в 1992 году и обновлена в 2013 году. Данный комитет изучил факторы, способные привести к мошенничеству в отношении финансовой отчетности, и разработал руководство «Внутренний контроль - интегрированная конструкция». COSO определяет внутренний контроль как «процесс, осуществляемый советом директоров, руководством и другим персоналом организа- ции, призванный обеспечить разумную уверенность в отношении достижения целей в следующих категориях: достоверность финансовой отчетности, результативность и эффективность совершаемых фактов хозяйственной жизнедеятельности, соблюдение применимых законов и нормативных актов»**.

Внутренний контроль за составлением финансовой отчетности позволяет достичь цели во всех трех вышеуказанных категориях. Основная направленность такого контроля - это обеспечение надежности информации, представленной в финансовых документах экономического субъекта, что в свою очередь невозможно без качественного выполнения сотрудниками своих обязанностей и соблюдения требований законодательства, что в целом проявляется в совершении фактов хозяйственной жизнедеятельности экономического субъекта.

Процесс формирования системы ВКФО согласно методологии SOX является значительным мероприятием для экономического субъекта и должен управляться как официальный проект.

Первоначально, руководство организации должно определить ответственное лицо из состава топ-менеджмента экономического субъекта,

* Sarbanes-Oxley Act.: (официальный сайт) - URL: http://www.sarbanes-oxley-101.com/

** The Committee of Sponsoring Organizations' (COSO): (официальный сайт) - URL: http://www.coso.org 
который сможет взять на себя ответственность за общее руководство проектом и доведение его до завершения. Обычно эту роль выполняет генеральный директор или финансовый директор. Далее необходимо выбрать членов проектной команды, определить их роли и обязанности, необходимые ресурсы, внутренние и внешние источники финансирования этих ресурсов. Также необходимо назначить непосредственного руководителя группы, им может быть главный бухгалтер или внутренний контролер.

Следующий шаг - разработка плана проекта, в котором должны быть установлены цели и задачи проекта, этапы его реализации и контрольные точки.

В процессе реализации проекта сначала требуется идентифицировать приоритетные элементы финансовой отчетности, оценить текущее состояние критических процессов, которые влияют на выбранные элементы финансовой отчетности, и документации по внутренним средствам контроля. Наиболее важными моментами на данном этапе являются определение ключевых элементов финансовой отчетности и выявление связанных с ними рисков.

При определении ключевых элементов финансовой отчетности следует учитывать ниже представленные факторы:

- использование оценочного суждения при определении сумм;

- степень подверженности мошенничеству;

- сложные требования к бухгалтерскому учету;

- чувствительность к технологическим и/ или экономическим изменениям;

- размер счета или группы связанных счетов (например, выручка и дебиторская задолженность);

- объем, размер, сложность и однородность отдельных транзакций, относящихся к данному счету или группе связанных счетов;

- наличие, характер и влияние сделок со связанными сторонами;

- использование ИТ-системы (например, SAP, Oracle, PeopleSoft, J.D.Edwards и т.д.), которая затрагивает всю организацию или ее важные части;

- степень зависимости от третьих лиц, включая специалистов и сервисные организации;

- возможные непреднамеренные или преднамеренные ошибки;

- масштабы изменения в бизнесе и его ожи- даемый эффект.

Также элементы финансовой отчетности должны выбираться в зависимости от того, есть ли вероятность существенной ошибки или искажения в данном элементе. Руководитель проектной команды и ее участники должны использовать свои знания бизнес-процессов экономического субъекта, организационной структуры, процесса подготовки финансовой отчетности, чтобы выявить источники и потенциальную вероятность искажений в финансовых элементах отчетности*.

Уровень существенности искажения финансовой отчетности может быть установлен в виде числового порогового значения, такого как 5\%, что подразумевает - отклонение менее определенного процента по отношению к конкретной статье в финансовой отчетности не будет являться существенным.

Но использовать только количественную оценку уровня материальности недостаточно. Существует много качественных факторов при оценке существенности, при учете которых материальность может оказаться ниже количественного порога. К таким факторам относятся следующие:

- возможно ли точно измерить искажение;

- является ли искажение результатом оценочного суждения;

- превращает ли искажение убыток в доход или наоборот;

- относится ли искажение к части бизнеса, являющейся одной из генерирующих наибольшую прибыль;

- влияет ли искажение на соответствие нормативным требованиям;

- влияет ли искажение на соблюдение договорных обязательств;

- влияет ли искажение на увеличение вознаграждения руководства;

- является ли искажение сокрытием незаконной сделки.

Достижение цели не будет возможным без наличия эффективной системы ВКФО. Модель данной системы, предложенная законом Sarbanes-Oxley, позволяет повысить качество внутреннего контроля, так как в ней детально продуманы все элементы системы ВКФО и особый акцент делается на тестировании эффективности внутренних контролей, как на этапе их разработки, так и в процессе выполнения.

\footnotetext{
* Benchmarking SOX Costs, Hours and Controls: (официальный сайт) - URL: https://www.protiviti.com/US-en/ insights/sox-compliance-survey.
} 


\section{Библиографический список}

1. Sarbanes-Oxley Act.: (официальный сайт) - URL: http://www.sarbanes-oxley-101.com/

2. The Committee of Sponsoring Organizations' (COSO): (официальный сайт) - URL: http://www.coso.org

3. Benchmarking SOX Costs, Hours and Controls: (официальный сайт) - URL: https://www.protiviti.com/US-en/ insights/sox-compliance-survey.

4. DeFond, M., Hung, M., Karaoglu, E., Zhang, J., 2007. Was the Sarbanes-Oxley Act good news for corporate bondholders? Working Paper, University of Southern California.

5. Hollis Ashbaugh-Skaifea, Daniel W. Collinsb, William R. Kinney Jr, 2007. The discovery and reporting of internal control deficiencies prior to SOX-mandated audits. Journal of Accounting and Economics 44: 166-192. 